\title{
Plant Species Composition and Distribution in Relation to Land Use Patterns in Serengeti Ecosystem Tanzania
}

\author{
Cosmas Mligo \\ Department of Botany, University of Dar es Salaam, Dar es Salaam, Tanzania \\ Email: $\underline{\text { mligo@udsm.ac.tz }}$
}

Received 30 April 2015; accepted 16 August 2015; published 20 August 2015

Copyright (C 2015 by author and Scientific Research Publishing Inc.

This work is licensed under the Creative Commons Attribution International License (CC BY). http://creativecommons.org/licenses/by/4.0/

(c) (i) Open Access

\begin{abstract}
Serengeti is the largest ecosystem in Tanzania endowed with high level of biodiversity in protected and unprotected areas. Serengeti National Park is the only protected area in a matrix of unprotected areas characterized with a wide range of human activities which threaten biodiversity conservation. It was assessed plant species composition, diversity, distribution and vegetation structure in both the protected and unprotected areas of the ecosystem. Two transects with twenty plots each were established in each vegetation type in which data was collected. A significantly higher species composition (262) and diversity $(2.39 \pm 0.03)$ was observed in unprotected areas than in the protected area (163 and $2.06 \pm 0.04$ respectively). The DCA ordination of the species data from the two management regimes formed four clusters based on similarity in plant species composition, where three clusters were from unprotected areas and one from protected area. The variations in plant species composition ranged from $35.69 \%$ to $65.92 \%$ for the first four DCA axes. There was no significant difference in stem density between protected and unprotected areas of the ecosystem. Although high density of trees at $10-14 \mathrm{~cm}$ DBH sizes was observed in both sides of the conservation management regimes, individuals with DBH above $65 \mathrm{~cm}$ existed in the protected area but were absent in unprotected areas. It can be concluded that the decrease of plant species diversity and density in unprotected area is because of habitat degradation associated with exploitation pressure, livestock grazing and other forms of disturbance related with anthropogenic activities. Because of high demand for plant resources, the local community needs to establish woodlots to cater for wood resource needs outside the protected areas of Serengeti. Also, pastoralists need to diversify livestock keeping systems compatible with limited grazing land in unprotected area of the Serengeti ecosystem.
\end{abstract}

\section{Keywords}

Composition, Community, Degradation, Diversity, Protected Area, Unprotected Area, Serengeti 


\section{Ecosystem}

\section{Introduction}

Serengeti is the largest ecosystem in Tanzania and being part among the well known world heritages with high level of biodiversity. The ecosystem is characterized by a broad spectrum of habitat diversity including woodlands, riverine forests, grasslands, wooded grasslands and shrublands harbouring diverse flora and fauna. The nested habitats provide attractive scenery of a typical African savanna ecosystem. Regardless of the diverse natural habitats and biodiversity, not all parts of the Serengeti ecosystem in Tanzania are protected. A protected area is an area of land delineated for maintenance of biological diversity (Mekonnen et al., 2009). It is an important "in situ" conservation technique (Lovejoy, 2006) that has been the most successful measure for conservation of biodiversity (CBD, 2003). However, a number of anthropogenic activities outside these protected areas make them vulnerable to environmental stresses and degradation. Because of habitat degradation, protected areas are the refugia of species (Laurance et al., 2012) and therefore reflect what is happening in the unprotected areas in the neighbouring habitats (Sjøgren, 2012). Serengeti National Park is a sole protected area in the ecosystem that forms the reference in this study. It is surrounded by a matrix of unprotected areas dominated with settlements, farmlands and game reserves that are an integral part of the Serengeti Ecosystem. Within this ecosystem, the biodiversity components have no habitat use choices between protected and unprotected areas as they may equally colonize the habitats that are in close proximity with the protected area. From biodiversity conservation point of view, Serengeti National Park can be described in terms of an island biogeography model within the ecosystem. Its position makes it be isolated from similar habitats present in the unprotected area and the biodiversity components cannot safely colonize favourable habitats within the ecosystem. In this context it can be regarded that habitat isolation is the most important factor that can endanger biodiversity in an ecosystem (Saunders et al., 1991; Gaston et al., 2008).

The Serengeti ecosystem contains natural biological resources of which human depend on for livelihood, survival and development and this has increased over years. Human dependence on natural biodiversity is not unique to the Serengeti ecosystem since this has been a global phenomenon. In the course of utilization of biological resources, overharvesting of plant species especially trees is the most common human activities in the ecosystem. This also includes vegetation clearance for cultivation and livestock keeping which have complicated the biodiversity conservation in Serengeti ecosystem. In the absence of conservation perception among local communities, the aforementioned anthropogenic activities cause habitat fragmentation and loss of biodiversity (Amutete, 2002; Nyawira, 2006). The local community in Serengeti ecosystem perceives that cropland and domestic pastureland provides immediate benefits than conservation. Although the major challenge is to increase food production and ensure food security for the growing population in Tanzania, parallel with conserving the environment, the process of land conversion and agricultural intensification are a significant cause of vegetation disturbance. This has subsequently impacted negatively both vegetation community structure and plant species composition. Following the growing concern on the ecosystem degradation caused by land use change, it was imperative to determine ecological parameters that highlighted the negative impacts of human activities on biological diversity in Serengeti ecosystem. It was aimed to determine plant species composition, diversity and tree stem density among vegetation communities in protected and unprotected areas of the ecosystem. It was based on the assumption that conservation promotes high plant species diversity and result into a stable plant population structure than other land use types in the Serengeti ecosystem..

\section{Material and Methods}

\subsection{Description and Location of the Serengeti Ecosystem}

Serengeti ecosystem is located in the northern part of Tanzania and south of Kenya between longitudes $1^{\circ} 30$ 'S $3^{\circ} 20^{\prime} \mathrm{S}$ and latitudes $34^{\circ} 00^{\prime} \mathrm{E}-5^{\circ} 15^{\prime} \mathrm{E}$ (Figure 1). Mara River is the largest perennial water body cutting across the ecosystem through the Kenya-Tanzania border and out of the protected area through Lamai gate to the Lake 


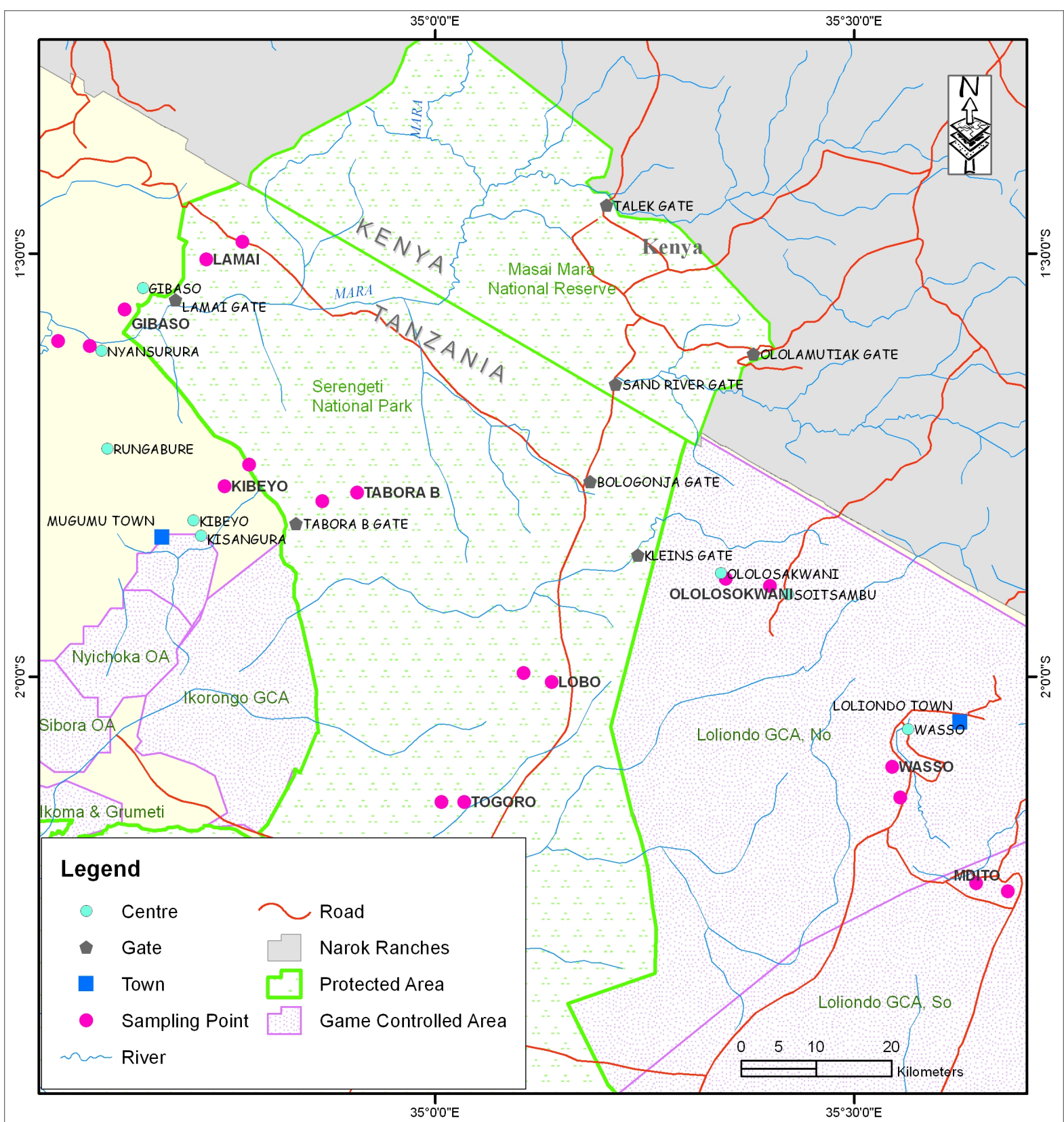

Figure 1. The Serengeti ecosystem showing the sampling sites in protected and outside the protected areas in Tanzania.

Victoria. Mara River is the major source of water for wildlife and human inhabiting in the riparian areas of the river system and hence being a trans-boundary resource wealth conserving (McClain et al., 2014). Within the ecosystem some of the wildlife habitats fall in protected areas and others outside the protected area. The protected area in Tanzania is bordered by the national border between Tanzania and Kenya to the north, which also continued to the Maasai Mara National Reserve in Kenya. To the southeast of the park is the Ngorongoro Conservation Area, to the south-west lies Maswa Game Reserve, and to the western border are Ikorongo and Grumeti Game Reserves whereas to the northeast lies Loliondo Game Control Area. The ecosystem is principally dominated by black cotton soils with skeletal granite crystalline rocky outcrops covered with volcanic soil layers in some parts. The landscape pattern in the ecosystem include a flattened terrain with undulating hills and valleys covered with woodlands, grasslands, riverine forest, wooded grasslands and a mixed vegetation types. The northeast and western zones are slightly wooded volcanic hills whereas the central zone of the ecosystem is a 
typical savanna wooded grassland supporting large ungulate populations. To the southern part of the ecosystem are open grassland plains. Serengeti ecosystem is partly wet on the west-north side and dry in the east-south, forming a rainfall gradient within the regional bioclimatic belt. The average annual rainfall ranges from $500 \mathrm{~mm}$ to $1150 \mathrm{~mm}$ and average annual temperature is $20.8^{\circ} \mathrm{C}$, which is often less than the diurnal variation (Sinclair \& Arcese, 1995).

\subsection{Location of the Study Area and the Sampling Sites in Serengeti Ecosystem}

This study was carried out in the northern part of the Serengeti ecosystem in Tanzania. The decision to select the northern part was made after a preliminary survey that ended up with identification of various biodiversity habitats in the ecosystem. This part of the ecosystem is characterized by a number of anthropogenic activities which contribute to the degradation of biodiversity habitats. As a result of the reconnaissance survey, the Serengeti ecosystem was subdivided into two zones the "protected and unprotected areas". A total of ten (10) sampling sites were established where six (6) sites were established in unprotected area, such that four (4) representing uncultivated but used as livestock grazing areas to include Kibeyo and Ololosokwani (that represented the woodland), Nyansurura and Wasso (represented grassland) and two (2) sites (Gibaso and Mdito) represented cultivated area i.e. croplands. The unprotected areas have been exposed to a wide range of human activities such as cultivation, settlement and livestock grazing in combination with poaching which is a common phenomenon in the ecosystem (Figure 1). This is because grasslands, woodlands and croplands in unprotected area support high density of wildlife (Elephants, Thompson's gazelle) that co-exists with livestock within a single habitat. The remaining four (4) sites were established in protected areas where Togoro and Tabora B represented woodland, Lamai and Lobo represented the grassland vegetation type (Figure 1). However, wildlife donot have habitat restriction as they roam about in different habitats and share niches with livestock outsite the protected areas in the ecosystem. This is because of the established human settlements that occurs just outside the boarders of the protected area and therefore forms part of a complex integration that consists of the conserved areas and unprotected area (with a range of activities) in the Serengeti ecosystem.

\subsection{Vegetation Sampling Procedures}

Two transects measuring $1 \mathrm{~km}$ long each were established in each of the sampling sites where plots of sizes 20 $\mathrm{m} \times 25 \mathrm{~m}$ evenly spaced at $50 \mathrm{~m}$ interval were established along the transect for sampling of trees. Shrubs were assessed using $2 \mathrm{~m} \times 5 \mathrm{~m}$ subplots that were nested within $20 \mathrm{~m} \times 25 \mathrm{~m}$. Grasses, herbs and seedlings were sampled using a subplot of $0.5 \mathrm{~m} \times 2 \mathrm{~m}$ which was nested within the bigger plots as recommended by Stohlgen et al. (1995). The basic information gathered on vegetation characteristics includes CBH for each tree, number of tree and shrub stems and the percentage cover of each species at the herbaceous layer (grasses, herbs and seedlings). Each plant species was identified to species level, however, for those species that proved difficult to identify in the field, samples were collected, pressed and later taken to the herbarium of the University of Dares Salaam where they were identified by matching with the herbarium specimens. The nomenclature follows that of Hubbard and Polhill (1952).

\subsection{Data Analysis}

The plant species diversity among study sites within Serengeti ecosystem was determined in terms of Shannon diversity index (Shannon \& Weaver, 1948) according to the formula that follows:

$$
\text { Diversity Index }\left(H^{\prime}\right)=-\sum_{i}^{\infty} p_{i} \ln p_{i}
$$

where $p_{i}=n_{i} / N$ and is the proportion of the total number of all species in a quadrat and $\ln =$ natural logarithm to base $e$.

The plant species evenness index $(E)$ was calculated using the formula as recommended by Alatalo (1981):

$$
\text { Evenness }(E)=\frac{H^{i}}{\ln S}
$$

where $H^{\prime}$ is the Shannon-Weaver diversity index and $S$ is the total number of species from each sampling site. The plant species composition, diversity, evenness and tree stem density between protected and unprotected area 
was compared by using two-sample t-test at 5\% significant level based on the Instat statistical software, version 3.06 (Graphpad Instat, 2003). Moreover, the tree stem density among sample sites was compared using two-way analysis of variance (ANOVA) (Graphpad Instat, 2003). Variations in plant species composition and distribution patterns among vegetation community types in both ecological conservation management regimes were assessed using detrended correspondence analysis (DCA) ordination based on the community analysis package (CAP) (Henerson \& Seaby, 1999).

\section{Results}

\subsection{Plant Species Composition and the Species Distribution in the Serengeti Ecosystem}

A total of 314 plant species were recorded from all study sites in Serengeti ecosystem where the unprotected area recorded higher plant species composition (262 species) than in protected (163 species) (Figure 2). However, out of the 314 plant species recorded in the ecosystem, 151 plant species were identified in unprotected area and 52 were recorded only in protected areas and 111 species were common between the two management regimes. The difference in species composition between protected and unprotected area was significant based on t-test $(\mathrm{t}=3.54, \mathrm{df}=198, P=0.005)$.

Ordination of sampled data showed high variation in species composition among clusters from protected and unprotected areas (Figure 3). Their percentages varied based on the weighted means of the variable scores (eigenvalues) that ranged between $65.92 \%$ and $35.69 \%$ for the first four DCA axes. The grouping of plant samples from the two management regimes formed four clusters where three clusters were obvious at the first axis from left to right of the ordination space and the third cluster emerged at the second DCA axis from the bottom up in the canodraw (Figure 3). From the DCA ordination, three clusters were from the unprotected areas and one cluster includes all samples from protected area plus a few from the unprotected area (Kibeyo site) that has been included by chance in this cluster because of high similarity in plant species composition with those from the protected area. The ordination pattern indicated a low gradient score by Ololosokwani (unprotected site), which was indicative of a less disturbed condition than it was for sites from protected area (Lobo, Togoro, Tabora B and Lamai) that were at the central position between the clusters from the unprotected area (Figure 3).

Both protected and unprotected areas were characterized by various vegetation types that form a typical savanna woodland, wooded grassland or savanna grassland with an obvious difference in plant species composition between them. Inside the protected areas around Tabora B was a conspicuous woodland community represented by Ozoroa insignis, Combretum molle and Elaeodendron buchananii, Kigelia africana, Ficus lutea and Commiphora africana whereas large part at Lobo site was dominated with Acacia robusta, Acacia seyal and Acacia tortilis. The Lamai and Togoro grasslands in the protected area were dominated by Themeda triandra coexisting with Ocimum basilicum, Portulaca oleraceae and Crinum papilosa with a few scattered trees. Ololosokwani and Kibeyo were woodlands in unprotected areas, while the former was dominated by Euclea divinorium, Olea europaea, Acacia drepanolobium and Acokanthera oppositifolia, the later sample sites was highly represented by Acacia robusta. The Ololosokwani woodland is a valuable habitat that increases the dynamic area to large mammalian (Elephants and Buffalos) species in Serengeti ecosystem. Wasso grassland was represented by Eragrostis superba, Monadenium stapeliodes and Cyperus rotundus whereas Aristida-Elionurus

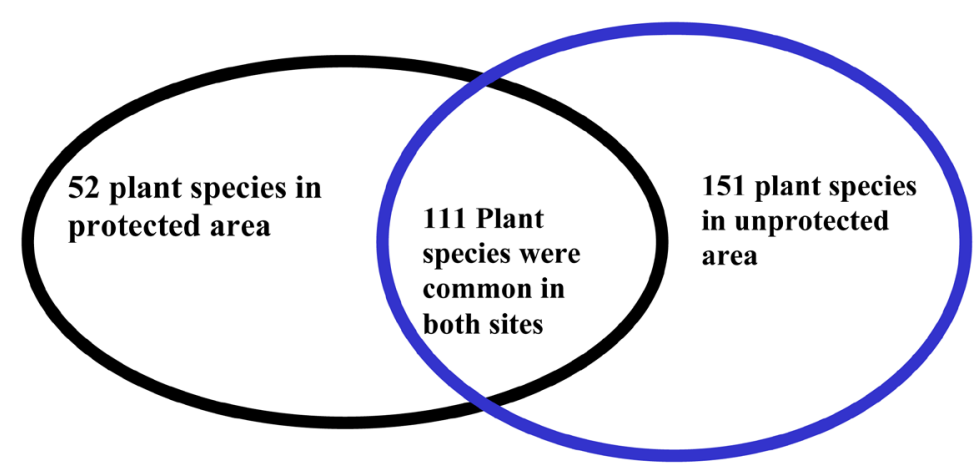

Figure 2. Plant species composition from both protected and unprotected area in Serengeti ecosystem. 


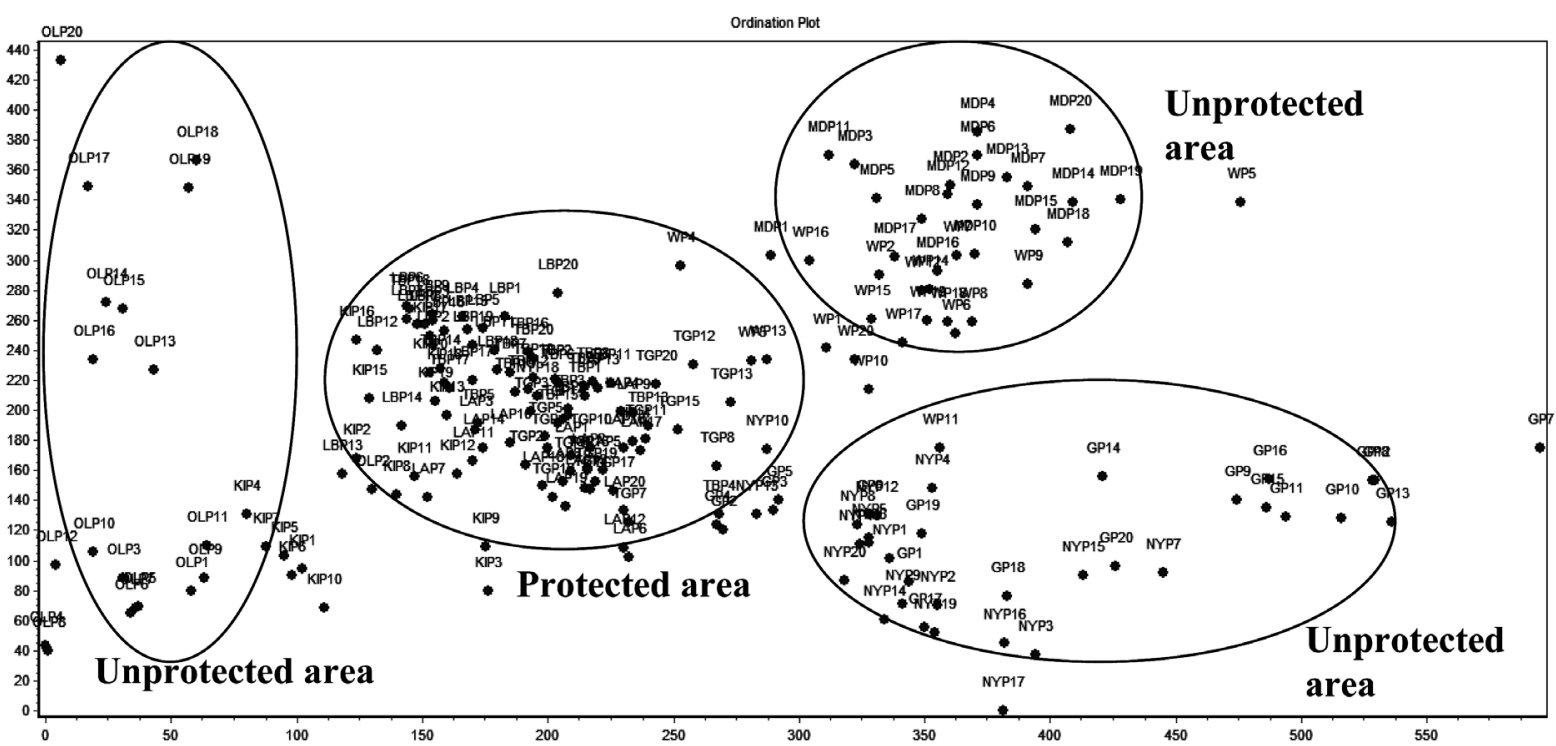

Figure 3. DCA ordination, showing clusters of samples based on management regimes in the Serengeti ecosystem. The sample sites in protected areas were $T B=$ Tabora $B, L B=L o b o, T G=$ Togoro, $L A=L a m a i$ and sample sites in unprotected area were $O L=$ Ololosokwani, $K=$ Kibeyo, $N Y=$ Nyansurula, $G=$ Gibaso, $W=$ Wasso, $M D=M d i t o, S N P=$ Sengereti $N a-$ tional Park.

community covered large parts in Nyansurula grasslands downstream of Mara River in the unprotected area. Gibaso and Mdito sites were disturbed through cultivation such that Aristida adoensis, Striga asciatica, Sesbania sesban, Vernonia poskeana and Tagetes minuta were the common weeds in these croplands. Amaranthus hybridus, Zea mays, Manihot esculenta, Sorghum bicolor, Eleusine coracana and Phaseolus vulgaris were the common crops grown at the expense of clearance of natural vegetation to provide food to the human population outside the protected areas in the Serengeti ecosystem. The protected area were commonly represented by native plant species with a few colonizing species in fire and wildlife disturbed habitats. However, in the unprotected areas weeds, colonizing plant species, a few stands of indigenous species and crops constituted the common plant species composition.

\subsection{Plant Species Diversity, Evenness and Richness in Serengeti Ecosystem}

It was found higher plant species diversity in unprotected areas with Shannon's diversity index in a range from 2.36 to 2.43 than in protected areas that was in a range from 2.02 to 2.12 which was significantly lower than in the aforementioned area based on the two-sample t-test $(\mathrm{t}=5.846, \mathrm{df}=198 ; p<0.0001)$ (also see Table 1$)$. This difference also applied to the Simpsons' diversity index, which was significantly lower in the protected than that in unprotected areas (Table 1). The plant species had the same level of evenness among sampling sites that ranged between 0.34 and 0.35 in protected areas and between 0.42 and 0.41 in unprotected areas. Based on t-test, the difference was significant and this also applied to the plant species richness between the two management regimes (Table 1 ).

\subsection{Tree Density among Sample Sites in the Serengeti Ecosystem}

The Ololosokwani sample site from the unprotected area recorded the higher number of individuals of trees than the rest of the sampling sites (Figure 4). This was followed by Lobo and Tabora B sites in the woodlands of the protected area where the Kibeyo site in the unprotected area has lowest tree stem density (Figure 4). The comparisons among sample sites showed significant difference based on the analysis of variance (ANOVA) (F = 4.88, $\mathrm{df}=75, P=0.0038$ ). However, Ololosokwani had a significantly higher tree stem density than Kibeyo $(\mathrm{LSD}=9.214, \mathrm{q}=4.980, P<0.01$ and Tabora $\mathrm{B}(\mathrm{LSD}=7.717, \mathrm{q}=4.050, P<0.05)$ whereas no significance difference existed between Tabora B and Lobo (from the protected) area (LSD = 3.592, $\mathrm{q}=1.885, P>0.05$ ) and this applied to the rest of the pairs of data. Also higher tree stem density was observed in unprotected than in the 
Table 1. The species diversity, evenness and richness in protected and unprotected areas of Serengeti ecosystem.

\begin{tabular}{ccccccc}
\hline \multirow{2}{*}{ Parameter } & \multicolumn{2}{c}{ Management Regime } & \multicolumn{3}{c}{ Statistical Test } \\
\cline { 2 - 7 } & Protected & Unprotected & T-Test & DF & P-Value & Conclusion \\
\hline Diversity $\left(\mathrm{H}^{\prime}\right)$ & $2.06 \pm 0.05$ & $2.39 \pm 0.03$ & 5.846 & 198 & $<0.0001$ & Significant \\
Evenness $(\mathrm{J})$ & $0.35 \pm 0.01$ & $0.41 \pm 0.01$ & 5.84 & 198 & $<0.0001$ & Significant \\
Richness & $10.0 \pm 0.52$ & $13.03 \pm 0.45$ & 3.076 & 198 & 0.0020 & Significant \\
Simpson & $10.23 \pm 1.30$ & $20.25 \pm 2.01$ & 2.971 & 198 & 0.0033 & Significant \\
\hline
\end{tabular}
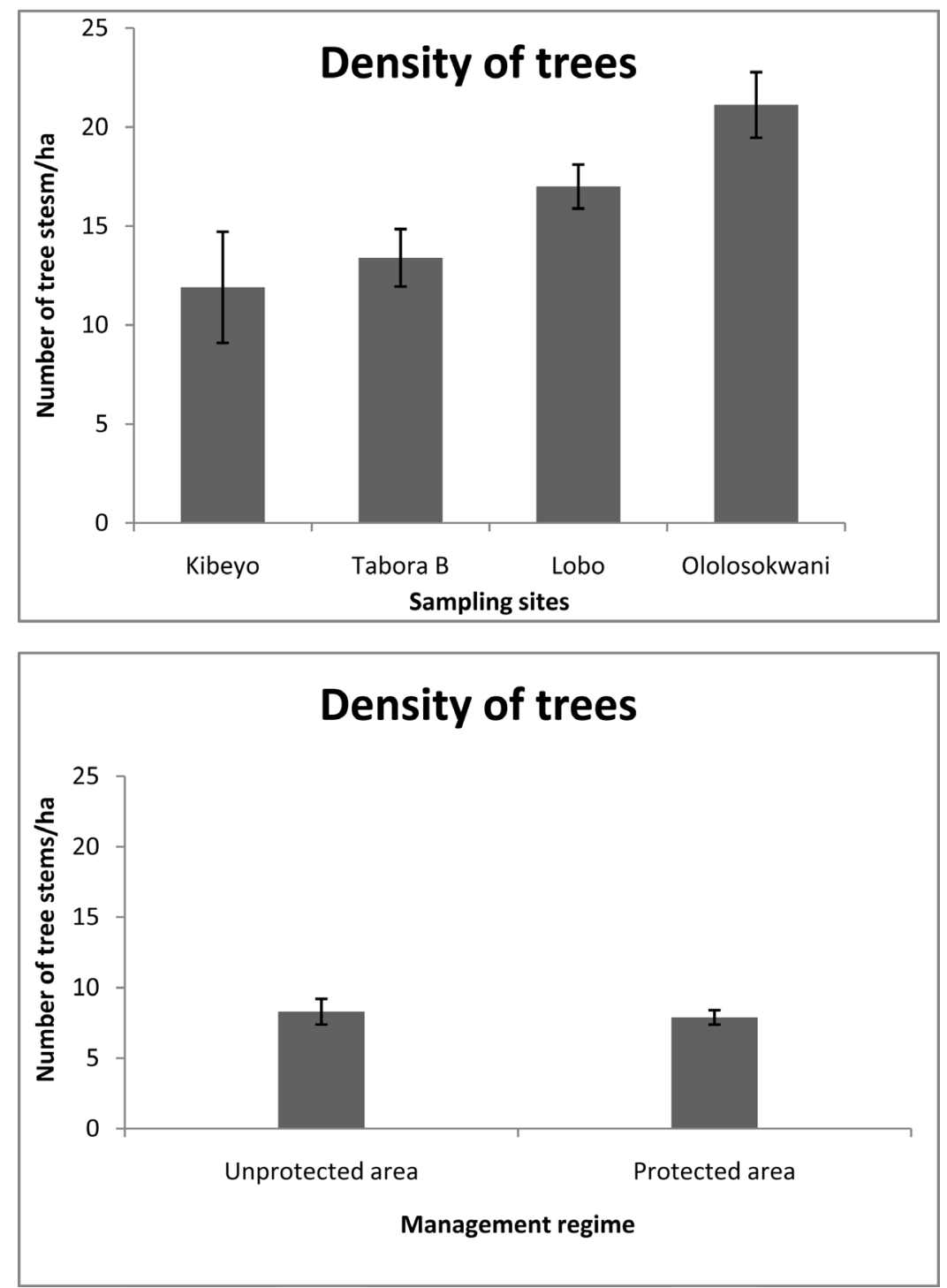

Figure 4. The density of tree stems among woodlands in protected and unprotected areas of the Serengeti ecosystem.

protected areas, however, the difference based on the two samples t-test was not significant $(P>0.05)$ (Figure 4).

\subsection{DBH Size Class Distribution in Serengeti Ecosystem}

The stand size class distribution pattern among tree species showed a considerable difference between the pro- 
tected and the unprotected areas such that high density was at lower sizes such that the population is characterized by individuals with DBH classes less than $24 \mathrm{~cm}$ (Figure 5). Both sides of the ecosystem had a population structure that displayed an inverted J-shaped curve with a high stem density at $10-14 \mathrm{~cm}$ size classes that progressively decreased with the increasing in girth sizes in both protected and the unprotected areas of the ecosystem. However, in the protected area, it was observed trees with girth sizes above $65 \mathrm{~cm}$, which were absent in unprotected areas (Figure 5). Higher stem density existed at $10-19 \mathrm{~cm}$ in unprotected areas than the protected area which showed a limited recruitment at lower size classes in the later management regime. A consistently low stem density of Acacia robusta at each size class, particularly at $10-14 \mathrm{~cm}$ and $15-19 \mathrm{~cm}$ size classes which was much lower outside the protected area than in the protected area. However, it was slightly higher stem density at lower girth sizes for Acacia nilotica in unprotected area than it was in a protected area. Large stem sizes of Acacia robusta beyond $39 \mathrm{~cm}$ were missing in the unprotected area, but existed in the protected area Figure 5. For A. nilotica, most trees had DBH sizes below $24 \mathrm{~cm}$ in the unprotected area where trees beyond these sizes were found in protected area. This indicates that exploitation of large size trees occurred in unprotected areas in the Serengeti ecosystem.

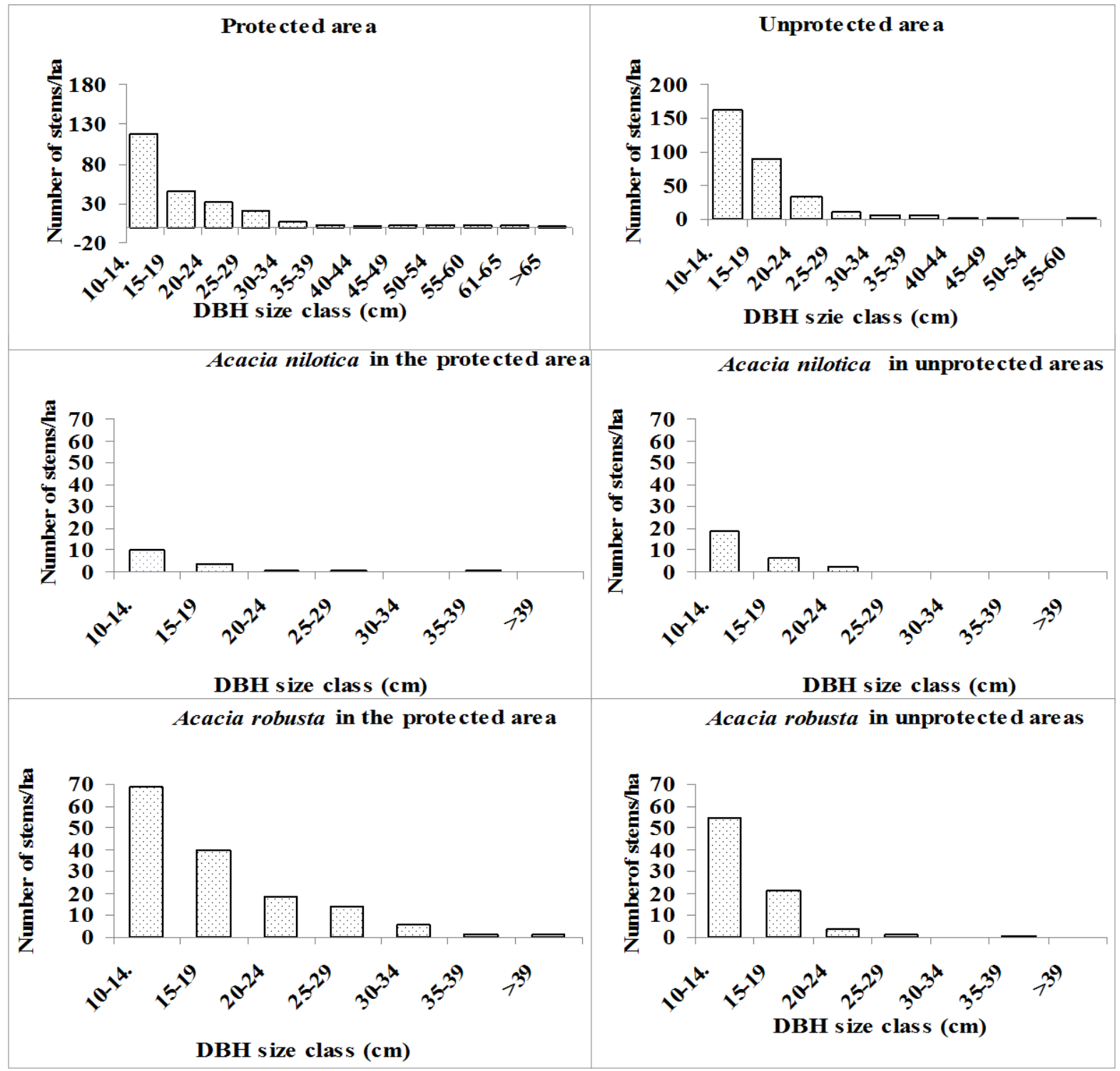

Figure 5. The DBH size class distribution of the dominant trees in protected and unprotected areas in Serengeti ecosystem. 


\section{Discussion}

\subsection{Variation in Plant Species Composition, Diversity and Distribution within the Serengeti Ecosystem}

Plant species composition and diversity varied between areas with different conservation management regimes in Serengeti ecosystem. It has been observed in many studies that protected areas recorded higher species diversity, evenness and density than unprotected areas (Thorington et al., 1982; Dhaou et al., 2010). This is based on the assumption that habitat protection reduces plant resource extraction that maintains higher plant species richness than in unprotected areas (Bruner et al., 2011; Andam et al., 2008; Joppa et al., 2008; Tang et al., 2011). However, it was observed a significantly higher plant species composition, diversity, richness and evenness outside the protected than in the unprotected parts of the ecosystem. This means, ecological parameters respond against a disturbance gradient and the level of protection within the ecosystem. This is contrary to the context of biodiversity conservation that the essence of habitat protection intends to maintain diverse biological components.

Although the unprotected areas were vulnerable to anthropogenic disturbance, they had high species richness and this portrayed that species composition changed along a coenocline as pointed out by Okland (1990). Exploitation and other forms of disturbance may result into habitat heterogeneity that provides a nurse effect for the establishment of diverse plant types and hence high species diversity and richness in unprotected areas. The sample sites from protected area were positioned between sites from the unprotected areas (Figure 3). Some plant species present in the protected area were absent in unprotected areas and some species were common among sample clusters from both types of management regimes within Serengeti ecosystem. Whilst the woodlands of the unprotected area were represented by Olea europaea, Acacia tortilis, Acokanthera oppositifolia, Acacia robusta and Euclea divinorum especially in Ololosokwani and Kibeyo study sites, the savanna woodlands, grasslands with patches of woody stands or scattered trees were common in the protected area. The Mdito site is part of unprotected area with a mixture of livestock grazing and crop cultivation; however it was largely dominated by the undisturbed Commiphora woodland. An extensive woodland cover with a pristine condition from an anthropogenic disturbance point of view indicates the importance of ecosystem services (pollinators) rendered by the woodland to the crop yield. Also, the pristine condition may be because of a great support on biodiversity conservation rendered by the local community causing little disturbance regardless of being part of the unprotected areas of Serengeti ecosystem. Because of large part being relatively undisturbed, the agricultural activities in these areas were regarded as an encroachment into the pristine habitat of the unprotected areas. Limited anthropogenic activities in the aforementioned site favoured the performance of plant communities with diverse life forms, including the lichens which are bio-indicator species of a pristine or less disturbed habitat conditions. The conserved trees in this area have become potential hosts of epiphytic orchids i.e. Acampe pachyglosa and Aerangis kirkii that have survived because of lower anthropogenic activities in Ololosokwani and Mdito than in the more degraded parts (Plate 1). From an ecological point of view, this part of Serengeti ecosystem contains plant communities that are at the reaction stage of succession towards climax status.

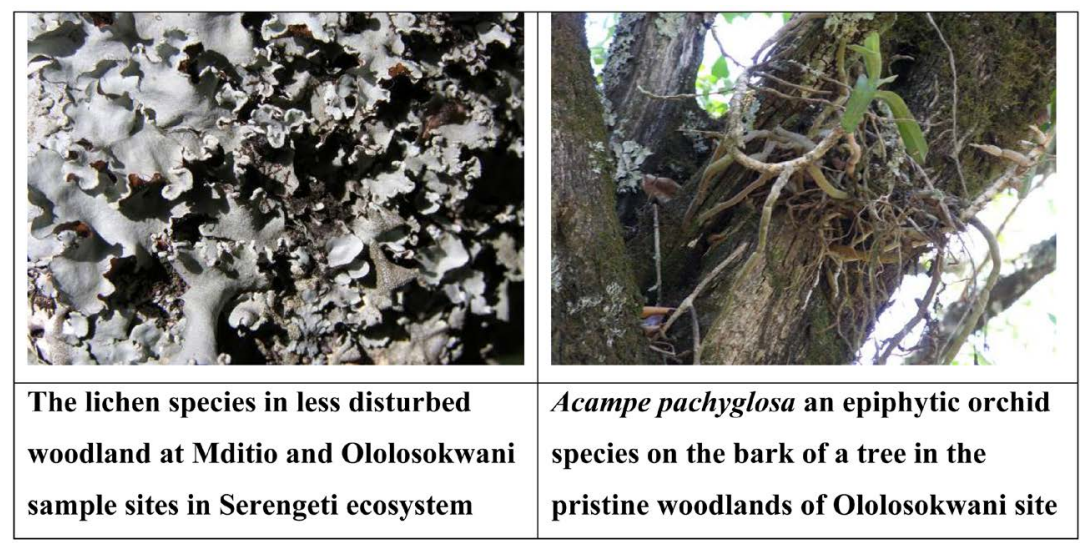

Plate 1. The pristine habitat indicator species (lichens and orchids) observed at Mditio and Ololosokwani in unprotected areas of Serengeti ecosystem. 
Presence of big sized trees of the Ozoroa insignis, Acacia robusta, Combretum molle, and Elaeodendron buchanani in Tabora B and Lobo sites in protected area is because of the absence of anthropogenic disturbance, exception the impacts of fire operation which is a common rangeland management tool in Serengeti wildlife savanna. The protected areas where Themeda triandra dominated, the trees were scattered especially in the grasslands at Lamai and Togoro sampling sites. The ability of Themeda triandra to re-sprout and emerge just after fire shows that it is tolerant to fire frequency. The vegetation community in the protected area is a savanna that has reached a climax status in the succession process such that they are dominated by a few plant species, particularly grasses with vigorous performance and high turnover rate upon disturbance by fire and grazing by wildlife. Halpern and Spies (1995) pointed out that burning favours domination of ruderal species. However fire adapted plant species are the dominant species in the protected areas and ruderal plant species colonized large parts of the unprotected areas in the Serengeti ecosystem.

Outside the protected area are a number of anthropogenic activities (for example, grazing pressure, cultivation, fire and exploitation) at different levels of intensities, which makes the two sides of the ecosystem vary in species composition and trees stem density. According to Moshi (2000), if the magnitude of disturbance increases beyond the irreparable level only the colonizing species with high growth and dispersal rate would be able to exist in a plant community. The anthropogenic activities in the unprotected areas affect pristine habitats and favour weeds, species invasion, species with higher dispersal rates to colonize (Aristida adoensis, Argemone mexicana, Mellinis repens, Striga asiatica, Hibiscus hybridus, Sesbania sesban, Vernonia poskeana, Launnea cornuta and Tagetes minuta) than the mono-dominant grass (Themeda triandra) in protected area. However, disturbance due to overgrazing in unprotected areas, the unpalatable grasses to livestock remains especially at Nyansurula grasslands that had a well-represented Elionurus muticus and Aristida adoensis (Plate 2). These grasses covered most of the hills and the entire landscape along the Mara River and were not preferred by livestock such that their luxuriant growth may be because of being unpalatable.

\subsection{Population Structure and DBH Size Class Distribution of Trees in the Serengeti Ecosystem}

It has been adequately described in various studies that the diameter size class distribution of woody plants are affected by the types of conservation management regimes (Schumann et al., 2010; Fandohan et al., 2011; Houehanou et al., 2013). The diameter class size distribution (DBH) for the pooled tree species data revealed a decrease in stem density with increased DBH size classes in both studied sites (Figure 5). Since the sampling sites were established in areas with different conservation status, this might have contributed to the differences in plant DBH size class distribution patterns. Outside the protected area is encroached by human activities through livestock grazing and cultivation, however, some larger mammals especially elephants have no habitat use boundaries as they can roam about in both sides of the ecosystem. In Ololosokwani which is outside the protected area, wildlife co-exists with domestic animals such that a combination of the effects of large populations of large mammals through browsing, grazing and knockdown of trees affected plant population structure.

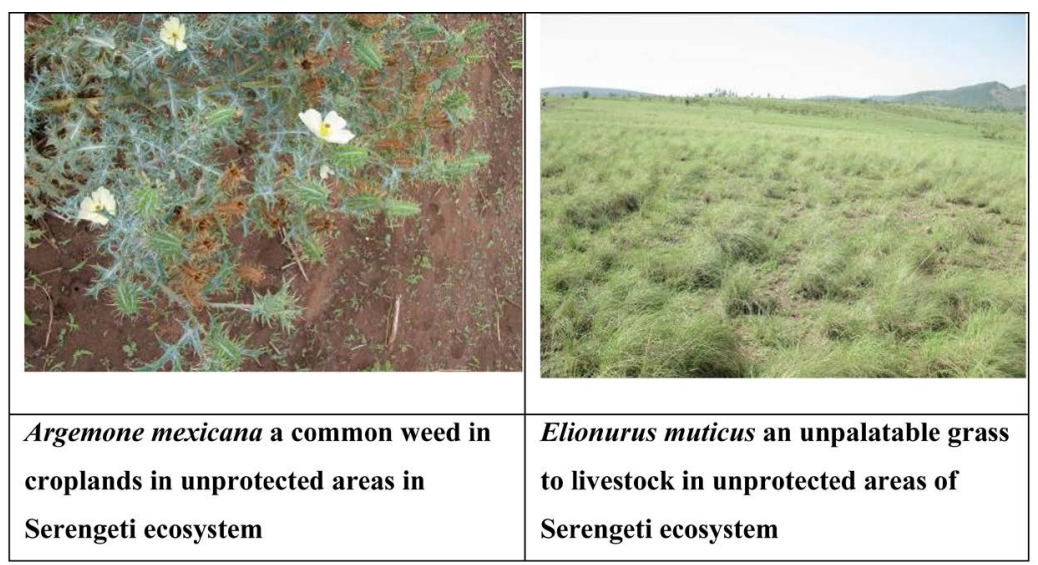

Plate 2. Argemone mexicana a common weed and Elionurus muticus an unpalatable grass to livestock in unprotected areas of the Serengeti ecosystem. 
Because of high pressure outside the protected area there were no individual trees with DBH size classes above $70 \mathrm{~cm}$ (Figure 5). Under intensive exploitation pressure targeting large trees, the population structure can be interrupted and trees with small sizes can also be exploited before attaining large growth sizes. Kumlachew and Taye (2003) pointed out that individuals with small size classes in a given population function as a significant reserve for replacing older individuals. Skewed curve to lower size classes is an indication of community structural succession (Diekmann, 1994). The size class distribution provides information about population structure and functions (Tsingalia, 1982; Mligo et al., 2009). However, the density of the recruits declines with increasing growth sizes due to mortality caused by fire and grazing in protected areas as well as clearance for cultivation and exploitation of trees in unprotected areas of the ecosystem. Because of the use of fire as the rangeland management tool inside the protected area, some of the trees may not be represented at lower growth sizes. The existing big trees in the rangelands of the protected area probably are relics of the previous vegetation communities that have been modified by wildlife grazing in combination with fire operation inside the protected area. The regular burning practiced in the protected area may justify the trends of population structures for trees as the main cause of mortality in the early life stages (Bationo et al., 2001). Natural regeneration requires successful seed germination and growth as pointed out by Nunamker and Valachovic (2007) and Lyaruu et al. (2000). However, individuals' survival chances are determined by the available limiting factors in both unprotected and protected area.

\subsection{The Effect of Anthropogenic Activities on Plant Biodiversity in the Serengeti Ecosystem}

To generate understanding on the impacts of anthropogenic activities on plant biodiversity in Serengeti ecosystem, the interpretation of data was based on the context of a complex paradigm. The paradigm is based on plant population assemblages where the natural ecological processes and human-biodiversity interactions have maintained the entire ecosystem over the years in the evolutionary history. However, the increased human dependence on natural biodiversity affected the historically balanced ecosystem in the ecosystem. Due to intensive human activities, fragmentation of the natural habitats has been the consequence (Plate 3). According to Brookfield et al. (2002), human has been transforming the environment over the years and the dependence on the biological diversity is at an alarming rate. High dependence on natural resources by the local community within the ecosystem has caused depletion in some parts such that an alternative resources need may be necessary.

Unprotected habitats are converted to cropland because of poor agricultural practices characterized by shifting cultivation as the land becomes quickly degraded. With a growing human population parallel with the increased anthropogenic activities, degradation of the unprotected habitats has grown in the ecosystem. This has caused increased scarcity of resources outside the protected areas, which are now obtained illegally from the adjacent protected areas. These activities have become a big threat to biodiversity in the protected area with an aggravated human wildlife conflict in the ecosystem. For example, the villagers in Tabora B and Kibeyo are depending on fuel wood from the nearby-protected area because it has been depleted outside the protected areas of
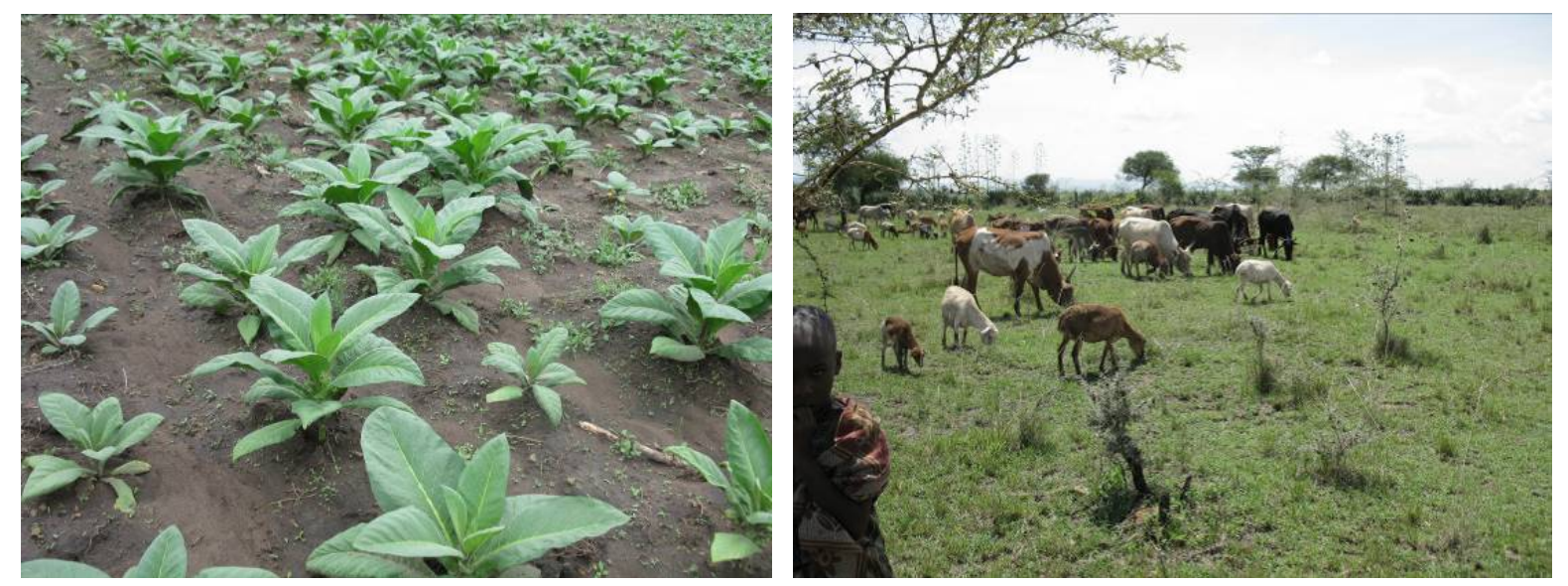

Plate 3. Tobacco farming and grazing degrading habitat in unprotected areas in Serengeti ecosystem. 
Serengeti ecosystem. Decreased grazing land due to increased livestock population makes the pastoralist invade the protected areas, resulting to an endless biodiversity resource use conflict with wildlife management of Serengeti National Park, which is the protected zone of the ecosystem that forms the core of this discussion. The massive transformation of the wild land in the ecosystem to grazeland and farmland means a large part of the natural habitats is lost and this is a primary threat to the plant species. The impact is aggravated by an ever increasing high level of anthropogenic activities associated with the increased biodiversity resource needs such that the remaining limited natural habitat in Serengeti ecosystem is degraded. Exploitation of trees outside the Serengeti ecosystem reduces population sizes and therefore their genetic variability, which may affect their ability to adjust to existing habitat changes.

However, most plant populations in the protected area (Serengeti National Park) are affected by fire that has been an integral part of the savanna ecosystem. Fire operations may have contributed to the disturbance of the natural habitats that resulted into uneven distribution pattern of plant species in the protected area within the ecosystem. Although the best part of fire operation is to maintain large grass cover, it affects the tree population structure by killing seedlings and small trees which limit their survival chances in the rangelands. The removal of grass cover through frequent livestock grazing outside the protected area minimizes the function rendered by seasonal burning in the ecosystem. Therefore fire application as pasture management tool outside the protected area becomes less important, because livestock grazing have reduced the fuel accumulation to the extent that the little plant remains do not support adequate burning. Therefore fire outside the protected area provides the desired minimum impacts and young trees are not killed by fire rather are affected by livestock browsing and/or other human uses.

\section{Conclusions}

It was found a significantly higher plant species composition, richness, diversity and evenness in unprotected than protected area in the Serengeti ecosystem. It was interpreted that disturbance might have increased habitat heterogeneity which provided favourable conditions that brought about nurse effects to support diverse plant species in unprotected areas. However, many plant species contributing to the high ecological parameters in unprotected areas were considered colonizers following disturbances through cultivation, livestock grazing and other forms of disturbances. Disturbance has disrupted the natural vegetation community and dragged it into its early stage of ecological succession. This brings about a strong justification for conservation of natural resource through designation of protection. The population structures showed that outside the protected areas, trees with large DBH sizes were missing due to overexploitation, but were found in the protected area.. This shows the importance of conservation and protection of natural habitats for plant biodiversity in the Serengeti ecosystem. If the environmental catastrophes induced by human activities are kept to the minimum outside the protected area, it is anticipated that many individuals could attain maximum growth sizes in the natural habitat.

A well defined niche separations and resource partitioning exists among wild herbivores in their respective habitats in the protected area of the Serengeti ecosystem. However, wild ungulates have no boundaries as they roam freely to access forage resource in both protected and unprotected areas in the Serengeti ecosystem where they can spatially co-exist with livestock in unprotected areas resulted into overgrazed conditions. Overgrazed condition outside the protected area is contributed by large populations of livestock in combination with the lack of pasture resource separation among domesticated herbivores. The pastoralists in the ecosystem illegally drive their livestock into the marginal zones in the protected area that has contributed to a significant degradation of natural wildlife habitat in such areas. Also, some resource in which human depends on has been depleted outside the protected areas and now the citizens obtain the same from the adjacent protected area. This contributes to degradation of the protected areas and the wildlife habitats are threatened. Because the unprotected area is heavily degraded following intensive anthropogenic activities, the demand for pasture suitable for livestock is growing. The local communities outside the protected area need to change from free range grazing to controlled grazing systems because of the limited pasture to support large populations of livestock. With the depleting wood resource outside the protected area, the local community needs to establish woodlots to provide fuel wood for domestic use and timber in unprotected areas of the Serengeti ecosystem.

\section{Acknowledgements}

The author is very grateful of TANAPA administration for the security support during the field work. Also the author is grateful to Mr. Suleiman Haji for his assistance during the field data collection of which the research 
was a success. Also it is highly acknowledged of a colleague in plant ecology field Professor HVM Lyaruu who went through the manuscript before submission to this journal for further scrutiny.

\section{References}

Alatalo, R. V. (1981). Problems in the Measurements of Evenness in Ecology. Oikos, 37, 199-204. http://dx.doi.org/10.2307/3544465

Amutete, G. (2002). Land Use Intensity Impacts on Biodiversity in Semi-Arid Areas: A Landscape Approach Using Birds. Dryland Biodiversity, 5, 27-28.

Andam, K. S., Ferraro, P. J., Pfaff, A., Sanchez-Azofeifa, G. A., \& Robalino, J. A. (2008). Measuring the Effectiveness of Protected Area Networks in Reducing Deforestation. Proceedings of the National Academy of Sciences of the United States of America, 105, 16089-16094. http://dx.doi.org/10.1073/pnas.0800437105

Bationo, B. A., Ouedraogo, S. J., \& Guinko, S. (2001). Seed Longevity and Stress Survival of Seedlings of Afzelia africana Sm. In savannah woodland in Burkina Faso. Annales des Sciences Forestieresm, 58, 69-75. http://dx.doi.org/10.1051/forest:2001107

Brookfield, H., Padoch, C., Parsons, H., \& Stocking, M. (2002). Cultivating Biodiversity: Understanding, Analyzing and Using Agricultural Diversity. London: ITDG Brookfield. http://dx.doi.org/10.3362/9781780441092

Bruner, A. G., Gullison, R. E., Rice, R. E., \& de Fonseca, G. A. B. (2011). Effectiveness of Parks in Protecting Tropical Biodiversity. Science, 291, 125-128. http://dx.doi.org/10.1126/science.291.5501.125

CBD (2003). Report of the Expert Meeting on the Global Strategy for Plant Conservation. UNEP/CBD/SBSTTA/9/INF/24. Montreal: Secretariat of the Convention on Biological Diversity.

Dhaou, S. O., Abdallah, F., Belgacem A. O., \& Chaieb, M. (2010). The Protection Effects on Floristic Diversity in a North African Pseudo-Savanna. Pakistan Journal of Botany, 42, 1501-1510.

Diekmann, M. (1994). Deciduous Forest Vegetation in Boreo-Nemoral Scandinavia. USA: Opulus Press AB, 116 p.

Fandohan, B., Assogbadjo, A. E., Kakai, R. L. G., \& Sinsin, B. (2011). Effectiveness of a Protected Areas Network in the Conservation of Tamarindus indica (Leguminosea-Caesalpinioideae) in Benin. African Journal of Ecology, 49, 40-50.

http://dx.doi.org/10.1111/j.1365-2028.2010.01228.x

Gaston, K. J., Jackson, S. F., Cantu-Salazar, L., \& Cruz-Pinon, G. (2008). The Ecological Performance of Protected Areas. Annual Review of Ecology, Evolution, and Systematics, 39, 93-113. http://dx.doi.org/10.1146/annurev.ecolsys.39.110707.173529

Graphpad Instat (2003). Graphpad Instat Software Inc., 3.06.

Halpern, C. B., \& Spies, T. A. (1995). Plant Species Diversity in Natural and Managed Forests of the Pacific Northwest. Ecological Applications, 5, 913-934. http://dx.doi.org/10.2307/2269343

Henerson, P. A., \& Seaby, R. M. (1999). Community Analysis Package. Pisces Conservation Version 1.5. Lymington: Pisces Conservation Ltd.

Houehanou, T. D., Assogbadjo, A. E., Kakaï, R. G., Kyndt, T., Houinato, M., \& Sinsin, B. (2013). How Far a Protected Area Contributes to Conserve Habitat Species Composition and Population Structure of Endangered African Tree Species (Benin, West Africa). Ecological Complexity, 13, 60-68. http://dx.doi.org/10.1016/j.ecocom.2013.01.002

Hubbard, C. E., Milnr-Redhead, E., \& Pohill, R. M. (Eds.) (1952). Flora of Tropical East Africa. London: Crown Agents for the Colonies.

Joppa, L. N., Loarie, S. R., \& Pimm, S. L. (2008). On the Protection of Protected Areas. Proceedings of the National Academy of Sciences of the United States of America, 105, 6673-6678. http://dx.doi.org/10.1073/pnas.0802471105

Kumlachew, Y., \& Taye, B. (2003). The Woody Species Composition and Structure of Masha-Anderacha Forest, Southwestern Ethiopia. Ethiopian Journal of Biological Sciences, 2, 31-48.

Laurance, W. F., Useche, D. C., Rendeiro, J., Kalka, M., Bradshaw, C. J., Sloan, S. P. et al. (2012). Averting Biodiversity Collapse in Tropical Forest Protected Areas. Nature, 489, 290-294. http://dx.doi.org/10.1038/nature11318

Lovejoy, T. E. (2006). Protected Areas: Prism for a Changing World. Trends in Ecology and Evolution, 21, 329-333. http://dx.doi.org/10.1016/j.tree.2006.04.005

Lyaruu, H. V., Eliapenda, S., \& Backeus, I. (2000). Floristic, Structural and Seed Bank Diversity of a Dry Afromontane Forest at Mafai, Central Tanzania. Biodiversity and Conservation, 9, 241-263. http://dx.doi.org/10.1023/A:1008954526896

McClain, M. E., Subalusky, A. L., Anderson, E. P., Dessu, S. B., Melesse, A. M., Ndomba, P. M., Mtamba, J. O. D., Tamatamah, R. A., \& Mligo, C. (2014). Comparing Flow Regime, Channel Hydraulics and Biological Communities to Infer Flow-Ecology Relationships in the Mara River of Kenya and Tanzania. Hydrological Sciences Journal: Hydrological Science for Environmental Flows, 59, 801-819. http://dx.doi.org/10.1080/02626667.2013.853121 
Mekonnen, M., Gebrehiwot, K., Birhane, E., \& Tewoldeberhan, S. (2009). Regeneration, Density and Diversity of Woody Vegetation in Awash National Park, Ethiopia. Journal of the Drylands, 2, 101-109.

Mligo, C., Lyaruu, H., Ndangalasi, H., \& Marchant, R. (2009). Vegetation Community Structure, Composition and Distribution Pattern in the Zaraninge Forest, Bagamoyo District, Tanzania. Journal of East African Natural History, 98, $223-239$. http://dx.doi.org/10.2982/028.098.0204

Moshi, G. Y. (2000). The Influence of Disturbance on the Status and Regeneration Rate of Selected Forests in the Udzungwa Mountains, Tanzania. Unpublished Master's Thesis, Dar es Salaam: University of Dar es Salaam.

Nunamker, C., \& Valachovic, Y. (2007). Forest Regeneration (pp. 826-827). Davis, CA: UC Agriculture \& Natural Resources.

Nyawira, M. M. (2006). Influence of Crotalaria/Tithonia and P Fertilization on Arbuscular Mycorrhizae Fungi Symbiosis in Maize. Master's Thesis, Eldoret: Moi University.

Okland, R. H. (1990). A Phytoecological Study of the Mire Northern Kisselbermosen, SE Norway. II. Identification of Gradients by Detrended (Canonical) Correspondence Analysis. Nordic Journal of Botany, 10, 79-108. http://dx.doi.org/10.1111/j.1756-1051.1990.tb01755.x

Saunders, D. A., Hobbs, R. J., \& Margules, R. C. (1991). Biological Consequences of Ecosystem Fragmentation: A Review. Conservation Biology, 5, 18-32. http://dx.doi.org/10.1111/j.1523-1739.1991.tb00384.x

Schumann, K., Wittig, R., Thiombiano, A., Becker, U., \& Hahn, K. (2010). Impact of Land-Use Type and Bark- and Leaf-Harvesting on Population Structure and Fruit Production of the Baobab Tree (Adansonia digitata L.) in a Semi-Arid Savanna, West Africa. Forest Ecology and Management, 260, 2035-2044.

Shannon, C. F., \& Weiner, W. (1948). The Mathematical Theory of Communication (pp. 150). Urbana, IL: University of Illinois Press.

Sinclair, A. R. E., \& Arcese, P. M. (Eds.) (1995). Serengeti II: Dynamics, Management, and Conservation of an Ecosystem (pp. 169-193). Chicago, IL: University of Chicago Press.

Sjøgren, K. (2012). Alarming Loss of Biodiversity in Protected Areas. ScienceNordic, September 20, 2012.

Stohlgen, T. J., Falker, M. B., \& Schell, L. D. (1995). A Modified Whittaker Nested Vegetation Sampling Method. Plant Ecology, 17, 113-121. http://dx.doi.org/10.1007/BF00045503

Tang, Z., Fang, J., Sun, J., \& Gaston, K. J. (2011). Effectiveness of Protected Areas in Maintaining Plant Production. PLoS ONE, 6, e19116. http://dx.doi.org/10.1371/journal.pone.0019116

Thorington Jr., R. W., Tannenbaum, B., Tarak, A., \& Rudran, R. (1982). Distribution of Trees on Barro Colorado Island: A Five Hectare Sample. In E. G. Leigh Jr., A. S. Rand, \& D. M. Windsor (Eds.), The Ecology of a Tropical Forest: Seasonal Rhythms and Long-Term Changes (2nd ed., pp. 83-94). Washington DC: Smithsonian Institution Press.

Tsingalia, H. M. (1982). Animal and Regeneration of African Rainforest Tree. Unpublished Master's Thesis, Oakland, CA: University of California. 